\title{
As Atitudes Políticas na Espanha, segundo uma estrutura dimensional indutiva
}

\author{
Araceli Mateos Díaz
}

Universidade de Salamanca

\begin{abstract}
Resumo
O artigo analisa as atitudes e percepções políticas dos espanhóis como constitutivas de sua cultura política, apontando o papel das atitudes políticas como um elemento necessário ao estabelecimento e consolidação da democracia no país. Apesar de concordar com a definição de Almond e Verba (1965) de que as atitudes políticas são englobadas pela cultura política, a autora apresenta uma crítica à sua classificação que divide as orientações em cognitivas, afetivas e avaliadoras e propõe que a distribuição das orientações não pode ser predeterminada, mas provém justamente da inter-relação entre elas. Em seguida, a autora propõe a construção de um modelo que distribua e agrupe os indicadores atitudinais diferentes dimensões. Embora as dimensões encontradas aproximem-se da classificação apresentada por Almond e Verba para a explicação do comportamento político, elas resultam de uma estrutura dimensional indutiva.
\end{abstract}

Palavras chave: cultura política, democracia, estrutura dimensional indutiva, comportamento político.

\begin{abstract}
The article considers attitudes and perceptions in Spain as aspects of the political culture, affirming the control role of the democratic political attitudes in the process of democratic consolidation. Although the author agrees to Almond and Verba (1965) definition that political culture includes political attitudes, the discusses their classification, which separates political orientations and political attitudes. She argues that distribution of orientations cannot be predetermined, and that results of their interrelations. The author presents a model of distribution and grouping the attitudinal indicators in different dimensions. The model resulted in a inductive dimensional schema.
\end{abstract}

Keywords: political culture, democracy, inductive dimensional structure, political behaviour. 
Depois de um quarto de século do restabelecimento da democracia na Espanha, os estudos sobre seus elementos constitutivos, sua inter-relação e o conhecimento dos processos que definem seu maior ou menor grau de qualidade alcançaram uma notável maturidade. A cultura política democrática é um elemento que, embora não seja qualificado na literatura como condição necessária e suficiente para a democracia, pode ser identificado como um fator explicativo de outros aspectos relacionados com seu desenvolvimento. A presença de atitudes políticas democráticas entre os espanhóis, inclusive antes do início do processo de transição, fez com que sua comparação com trajetórias políticas similares ficasse mais limitada. A coexistência dessas atitudes com uma situação política autoritária fez supor que o caso espanhol fosse um âmbito de estudo atípico se comparado com o europeu ocidental. Não obstante, a Espanha aparece como caso de comparação nos trabalhos que analisam as diferenças atitudinais levando em conta as ondas de democratização (POLLACK, 2003).

A definição mais ampla de cultura política faz referência ao conjunto de orientações políticas, incluindo opiniões, crenças, valores, atitudes e percepções dos cidadãos de uma determinada coletividade sobre objetos políticos. Nos termos clássicos de Easton (1965), esses objetos políticos referem-se tanto aos elementos que têm a ver com a estrutura como com o processo e com resultado do sistema político. Dentro desta perspectiva, as pesquisas que tratam de apresentar as características definidoras da cultura política de um país analisam atitudes tanto em relação à estrutura como ao processo ou ao resultado do sistema político. Almond e Verba (1965) estabeleceram uma classificação das atitudes em orientações políticas cognitivas, afetivas e avaliadoras. Essa tipologia se justifica na natureza que dá origem às atitudes políticas, embora tenha a desvantagem de que algumas atitudes políticas possam ser ao mesmo tempo afetivas e cognitivas, afetivas e avaliadoras, ou cognitivas e avaliadoras. Neste artigo, apresento um modelo alternativo de esquema dimensional das atitudes políticas dos espanhóis, no qual as dimensões não provêm de uma distribuição predeterminada delas mas da própria inter-relação entre essas atitudes.

A primeira parte apresenta um reexame dos conceitos de atitude política e cultura política e uma análise das diferenças ou relações conceituais e teóricas estabelecidas entre as atitudes e outros conceitos como valores, crenças e opiniões. A segunda seção conecta elementos teóricos e metodológicos na análise das atitudes políticas e a terceira, finalmente, apresenta um esquema dimensional que permite decifrar algumas das relações entre as atitudes políticas dos espanhóis. 


\section{As atitudes políticas como componentes da cultura política}

Uma atitude é a soma de inclinações e sentimentos, preconceitos ou distorções, noções preconcebidas, idéias, temores ou ameaças e convicções de um indivíduo sobre qualquer assunto específico (THURSTONE, 1984). Por sua vez, uma opinião constitui a expressão verbal de uma atitude. A opinião tem relevância como símbolo da atitude, mas o que realmente interessa é a atitude. No entanto, as opiniões e ações também podem ser distorções das atitudes. Em muitas ocasiões, existe certa discrepância ou algum erro de medida entre a opinião sustentada e a ação manifesta, e entre estas e a atitude. Nem sempre as opiniões e os atos manifestos constituem a melhor vitrine das orientações subjetivas e das preferências que formam uma atitude ${ }^{1}$. Froman (1962) diferencia entre crença, atitude e valor: o valor é o desejável, o que se quer, o que poderia ser, a relação de coisas que se consideram como uma finalidade. As crenças são utilizadas para descrever o que nos rodeia, podem referir-se a crer em algo ou crer sobre algo e costumam ter um significado adicional sobre se isso é verdadeiro ou falso. Por último, para esse autor, uma atitude é uma predisposição individual a avaliar um aspecto de seu mundo como favorável ou desfavorável, ter uma predisposição a aprovar ou desaprovar algo. Para ele, as atitudes podem ter dois componentes: afetivo (gostar ou não gostar de algo) ou cognitivo (acreditar ou não acreditar). Para outros autores (JAROS e GRANT, 1974, p. 252) em lugar desses componentes haveria um componente avaliador e um componente de crença. O avaliador seria definido pelo que nos agrada e o que não nos agrada (que corresponderia ao afetivo de Froman) e estas avaliações têm duas propriedades fundamentais: a direção e a intensidade. O componente de crença de uma atitude tem a ver com a qualidade e o grau de informação que está por baixo do componente avaliador. A estrutura particular de um sistema de crenças depende das inter-relações mantidas entre suas atitudes. Por seu lado, as atitudes políticas contêm três elementos: um conteúdo emocional ou afetivo; um elemento cognitivo, o que a gente sabe ou acredita que é certo; e a intenção de atuar que proporcionam em uma direção ou outra (ZUCKERMAN, 1991, p. 53).

A diferença entre as crenças e as atitudes está no fato de que as primeiras têm a ver com a natureza do mundo e as segundas são orientações em relação a objetos específicos (ALLEN, 1974, p. 71). As atitudes políticas podem ser o resultado da combinação de valores e crenças, sendo baseadas em crenças sobre coisas, eventos ou fenômenos políticos. Estas atitudes constituem uma organização persistente de predisposições em relação àqueles objetos. Considerar as atitudes

\footnotetext{
1 No caso aqui tratado, o exemplo mais claro seria o de ter uma opinião favorável em relação à participação política dos indivíduos, mas depois não ir votar e entre isso e ter uma atitude positiva perante o sistema político democrático e as eleições como mecanismo de representação.
} 
como sinônimos de predisposições implica entendê-las como uma construção teórica (JAROS e GRANT, 1974) ou como uma abstração analítica (KANAVAGH, 1972, p.14), o que implica que possam fazer referência, inclusive, a coisas que não são reais, que não podem ser observadas. Os defensores da inclusão do comportamento na definição de cultura política ou que a definem como uma extensão das atitudes políticas não costumam levar em conta essa definição. Sears chega a diferenciar entre predisposições atitudinais e predisposições simbólicas. As primeiras teriam um impacto maior nas avaliações que os adultos fazem dos objetos políticos, enquanto as simbólicas seriam aquelas adquiridas desde tenra idade e seriam estáveis até a idade adulta (SEARS, 2001, p. 17).

Um valor é definido como uma crença permanente que permite transmitir o objetivo da vida, é pessoal e socialmente transmitido. Os valores permitem adivinhar os objetivos vitais através de objetivos e situações específicos. Os valores são os que incorporam os objetivos para os quais os indivíduos devem dirigir-se. As atitudes são conjuntos de crenças enfocadas em um objeto particular ou situação, e proporcionam uma resposta favorável ou desfavorável, facilitam a predisposição de um indivíduo. O sistema de crenças é amplamente reconhecido por suas interconexões: as atitudes, crenças, valores, necessidades e interesses com freqüência mostram altos níveis de consistência cognitiva uns com outros (BRAITHWAITE, 1998, p. 48).

O conceito de cultura política teve um impacto de maior alcance na década de 1960, com a aparição do livro de Almond e Verba (1965), obra que se destacou por seu caráter inovador ao ver-se envolvida na revolução behaviorista da época e nos desenvolvimentos teóricos funcionalista e sistêmico (MORÁN, 1996, p. 11)2. Esses autores deram uma primeira definição de cultura política sustentando que: "a cultura política de uma nação é uma particular distribuição dos padrões de orientações em relação a objetos políticos entre os membros de uma nação"3 (ALMOND e VERBA, 1965, p. 15). Com isso, referiam-se às orientações políticas, isto é, às atitudes em relação ao sistema político e suas diversas partes assim como ao papel que cada indivíduo tem dentro do próprio sistema político. Se a cultura política conecta os dois níveis da política (macro e micro), então, por um lado, pode ser entendida como o resultado da história coletiva do sistema político e, por outro, das experiências pessoais dos próprios indivíduos. A cultura política englobaria o conjunto de significados compartilhados da vida política e o conjunto de recursos

\footnotetext{
2 A concepção parsoniana e funcionalista de cultura política assumia que esta era o principal instrumento de coesão social. Essa concepção trazia consigo a impossibilidade de estabelecer qual era o sentido da relação entre os valores, crenças e atitudes e os comportamentos concretos dos indivíduos. Além disso, tinha problemas para explicar o conflito e a mudança social (MORÁN, 1996).

3 Anteriormente, Almond já havia definido cultura política como "uma tendência particular de orientações da ação política, em que todo sistema político está assentado" (ALMOND, 1956, p. 396).
} 
utilizados para pensar sobre o político, o que supõe que é algo mais do que a soma das opiniões privadas dos indivíduos. Além disso, supõe a própria definição dos indivíduos como atores políticos, a forma como as pessoas constroem sua visão do político e sua posição dentro dele (MORÁN, 1996, p. 7).

Entre os níveis macro e micro da política, pode-se identificar um nível intermediário, denominado por alguns autores de mesonível, que se refere às regras do jogo aceitas por todos os cidadãos e que permite a conexão entre o sistema político e os indivíduos. Este mesonível está aberto à influência de como se desenvolve o debate político no nível micro. Por conseguinte, a microcultura política é composta por aquelas atitudes e orientações que têm a ver com a atividade política cotidiana (GIRVIN, 1989, p. 35).

$\mathrm{Na}$ formação dessas orientações, a socialização adquire uma grande importância. Se partimos da idéia de que determinadas características atitudinais dos cidadãos estão condicionadas pelo contexto político e social em que essas atitudes estão se formando (ou se formaram), é importante levar em conta como são o contexto e os processos de socialização que influíram na formação das orientações ${ }^{4}$.

Não existe muita diversidade nas definições de cultura política, mas há algumas abordagens que insistem de maneira mais específica na definição dos elementos ou atitudes que a compõem e o ponto de vista que se utiliza para interpretar sua continuidade ou mudança. Assim, por exemplo, encontramos aquelas que enfatizam que é o produto da história coletiva de um sistema político e o resultado da história pessoal dos membros desse sistema (PYE, 1968, p. 218). Outras definições ressaltam mais o peso dos valores e das atitudes que são compartilhadas no seio de uma sociedade e transmitidos de geração em geração (INGLEHART, 1991, p. 5), enquanto outras ainda, em lugar de considerar os valores, insistem no conjunto de "crenças" compartilhadas que têm conseqüências políticas (LANE, 1992) ou que legitimam determinadas práticas sociais (WILDAVSKY, 1987).

Se a cultura política inclui em sua definição a característica daquilo que é compartilhado, as atitudes políticas podem chegar a ser entendidas também como um fator de integração e de autoidentificação, já que permitem a formação de uma identidade coletiva ${ }^{5}$. Não obstante, alguns autores não concordam que as atitudes tenham essa função integradora, considerando que elas possam ser tanto um

\footnotetext{
4 "Citizens form opinions about politics by evaluating information that is filtered through the social environment in which they live. The implication is that social context, or an evaluation of a social context, is embedded as an element in the cognitive structure an actor employs to encode and store information" (MACKUEN and BROWN, 1987, p. 471).

${ }^{5}$ A cultura como mecanismo integrador foi defendida por Parsons, sendo a socialização política a encarregada de garantir essa integração.
} 
instrumento integrador como desintegrador, já que ao orientar as ações dos indivíduos, podem gerar conflito ou cooperação. Posto que proporciona um significado para as ações dos indivíduos, a cultura é capaz de produzir conflitos e, neste caso, é socialmente desintegradora (EDER, 1996, p. 96). Rosenbaum (1975) havia diferenciado entre sociedades fragmentadas e integradas. Uma sociedade desintegrada do ponto de vista das atitudes políticas é aquela em que há grupos isolados e separados que têm orientações políticas contraditórias ou incompatíveis em relação a vida política. Para esse autor, sociedades com um alto pluralismo social podem dar lugar a sociedades altamente fragmentadas. Essa fragmentação seria condicionada por um domínio das lealdades políticas paroquiais, por uma presença de violência política e desacordo com as regras e normas civis, assim como pela presença de desconfiança política entre os grupos sociais. Por outro lado, as sociedades altamente integradas politicamente se caracterizariam por ter uma alta consistência e identificação política, apresentando baixos níveis de violência política, um domínio civil dos procedimentos na hora de manejar os conflitos, amplas técnicas de colaboração política, apesar da diversidade, importantes lealdades ao regime e alta legitimidade da forma de governo.

Alguns autores consideram a cultura política como um fenômeno coletivo que se constrói socialmente e que se refere ao processo de interpretação dos significados da vida política (BENEDICTO, 1997, p. 228). Nesse processo de construção social de significados intervém uma série de fatores: as tradições sociais e políticas de uma determinada sociedade, a ação das elites como produtoras e transmissoras de significados e as pautas de interação dentro de uma estrutura social determinada. Outras definições, em lugar de fazer referência às orientações políticas, destacam a importância das suposições, consideram que a cultura política consiste em adotar uma atitude em relação ao mundo político, isto é, centram a atenção em eventos, instituições e comportamentos; definem o que é o realmente factível, identificam possíveis problemas e permitem tomar decisões, supõem uma disposição a favor entre uma gama de possibilidades. O espectro de atitudes e premissas que coexistem em uma cultura deve ser muito consistente e estar intimamente correlacionado (ELKINS \& SIMEON, 1979, p. 132).

Na segunda metade da década de 1990, apareceram novas concepções ou interpretações das atitudes políticas, derivadas de mudanças na definição de cultura política, como foi a "concepção mundana da cultura política". Esta definição insistia em ressaltar a importância das conversações cotidianas, o conjunto de intercâmbios com os quais os indivíduos interpretam o político e seus resultados, aqueles âmbitos em que as atitudes se formam. A cultura política mundana ajudaria a explicar a estabilidade política, posto que esta podia estar baseada na própria inibição dos cidadãos na participação política nas instituições. Junto com essa definição, é preciso destacar a aparição do termo "nova cultura política" (New 
Political Culture - NPC) e o de "cultura pós-moderna" (MERELMAN, 1998, p. 530) ${ }^{6}$. Para Clark e Inglehart (1998), a nova cultura política indica que existem diferenças com relação a sete elementos-chaves: a) a clássica dimensão esquerda-direita se transformou, as definições e os significados que se dão de esquerda e direita são diferentes dos que eram dados tradicionalmente; b) as questões sociais e econômico-fiscais são distinguidas explicitamente. Não existe uma superestrutura ideológica que marque as diferenças das posições mantidas em relação às questões sociais. A nova cultura política reflete uma maior diferenciação socioeconômica e profissional; c) as questões sociais adquiriram uma maior importância em relação às questões econômicas e fiscais; d) há um crescimento do individualismo social e do mercado; e) ocorre um questionamento do Estado de bem-estar. Alguns defensores da NPC manifestam que a manutenção de um Estado central planejador é muito pouco realista em relação a muitos serviços sociais e econômicos; f) há um aumento das questões políticas e uma ampla participação dos cidadãos, ao mesmo tempo em que ocorre uma queda das organizações hierárquicas; g) essa nova forma de definir a cultura política aparece muito mais clara entre as opiniões dos jovens, das sociedades mais educadas e mais individualistas.

Tanto a nova cultura política como a cultura pós-moderna mantêm uma relação estreita com a aparição dos novos valores pós-materialistas e a mudança nas preferências sociais, assim como nas demandas feitas ao Estado e o que se espera dele. Quanto à capacidade de contemplar a explicação da mudança, esta nova maneira de entender a cultura política implica uma diferença no que tange à sua definição clássica, ainda que a incorpore. O pós-modernismo é uma corrente que trata de explicar as condições culturais e os efeitos causados pelas mudanças econômicas, sociais e políticas. Ele inclui uma concepção da cultura política em que os valores individuais mudam tal como o faz o mundo contemporâneo. Existe, portanto, uma proliferação de novos valores, atitudes políticas, estilos de vida e movimentos sociais.

Neste artigo, as atitudes políticas estariam dentro da definição clássica de cultura política de Almond e Verba, entendida como a distribuição particular de pautas de orientação em relação aos objetos políticos, que resulta de uma história política compartilhada pelos cidadãos e de alguns elementos apreendidos e interiorizados por meio da socialização, graças aos quais se pode dar significado a

\footnotetext{
6 Quanto à importância da modernização e pós-modernização na mudança de valores, ver Inglehart (1998). Para o caso espanhol, Rojo (1992) realizou uma análise tentando comprovar os supostos da nova cultura política aplicando-a ao comportamento de voto dos madrilenhos. Neste caso, a nova cultura política supõe a perda de lealdade aos partidos e a diversificação social de suas bases, a perda do voto de classe. Segundo esta autora, "a nova cultura política tem possibilidades de se expandir na Espanha" por uma equiparação ao desenvolvimento pós-industrial, que fez com que aparecessem valores pós. materialistas, embora sua incorporação total dependa da absorção da modernidade por parte dos estratos sociais de menor nível educacional.
} 
esses objetos políticos. No entanto, essas pautas de orientação respondem não somente a atitudes, mas também a alguns comportamentos, concretamente, aos que se referem à participação política não convencional e à participação social. Esses comportamentos não são mais do que o prolongamento ou a expressão das atitudes mantidas ${ }^{7}$. Por outro lado, a distribuição particular das pautas de orientação não responde a algo pré-estabelecido teoricamente, uma vez que essa estrutura é criada ao longo desta pesquisa a partir das respostas dos cidadãos.

\section{Perspectivas teóricas na análise das atitudes políticas}

Cada definição de um conceito permite operacionalizá-lo em dimensões mensuráveis por cada pesquisador. Mas, por sua vez, essa operacionalização pode ser condicionada pela perspectiva teórica da análise. A teoria da cultura política a define, em primeiro lugar, como composta por uma série de concepções subjetivas que prevalecem na sociedade. Em segundo lugar, considera que possui componentes cognitivos, afetivos e avaliativos. Em terceiro lugar, parte de que seu conteúdo é fruto da socialização política e das experiências adultas. Finalmente, sustenta que afeta a estrutura e o desempenho político e governamental (ALMOND, 1999, p. 203).

O estruturalismo refere-se principalmente às reações das pessoas perante a política, busca as diferenças entre o que se espera e o consenso que existe diante de determinados aspectos políticos. Essas reações sobre a cultura e a política se fazem através de representações coletivas que, por sua vez, provêm do lugar que uma ou outra pessoa ocupa dentro da estrutura social. A teoria cultural pode enquadrar-se como derivada da abordagem estruturalista; para ela, os interesses políticos não podem ser analisados da perspectiva econômica ou racional, pois estão ligados às relações que os indivíduos estabelecem com seus grupos de referência e que, por meio de sua participação na política, vão criando suas próprias preferências e opiniões (WELCH, 1993).

A perspectiva culturalista estabeleceu quatro elementos caracterizadores de uma cultura. Em primeiro lugar, a cultura está relacionada com a sociedade, constitui uma determinada maneira de pensar e agir. Em segundo lugar, considera que a cultura é vida social em uma série de aspectos: crenças, conhecimento, moral, leis, costumes e hábitos de uma sociedade. Em terceiro lugar, a cultura é o

\footnotetext{
7 "Political culture and political behaviour cannot be kept hermetically separated to arguing that they should therefore be subsumed under the same rubric. ... Nor is it possible to explore the links between the internal world of values, feelings, and beliefs and the external world of behaviour if the two realms are conflated" (EVERITT \& O’NEILL, 2002). "Political culture must be limited to the attitudes, beliefs, and sentiments that give order and meaning to the political process and provide the underlying assumptions and rules that govern behaviour" (ROSENBAUM, 1975, p. 6).
} 
que diferencia uma sociedade de outra. Por último, a cultura é diferenciadora, é uma variável que une um conjunto de modos de pensar mediante os quais normalmente se regula o comportamento social (ECKSTEIN, 1988).

O funcionalismo entende a cultura política como o conjunto de interconexões lógicas entre as preferências, os interesses e as concepções das necessidades e dos recursos, assim como a contribuição de cada um para perpetuar um estilo de vida como parte do contexto político de uma sociedade. Para ele, existe o que Parsons definiu como "action frame of reference", segundo a qual o indivíduo está situado em um contexto que lhe proporciona informação sobre os objetos políticos e, ao mesmo tempo, aprende a reagir diante de situações (WELCH, 1993).

A quarta das perspectivas teóricas é a teoria sistêmica, que considera a política um sistema que sobrevive dependendo de como se proporcionem os outputs que esse determinado sistema necessita. A cultura política, segundo essa teoria, está situada fora do entorno político ou do centro do comportamento e da atividade. As normas culturais transmitidas através de gerações regulam as demandas dos cidadãos, o que se espera deles enquanto cidadãos ou em cooperação com outros, assim como o que é aceitável em uma sociedade. Os valores e as crenças de uma cultura política podem evitar também que se façam certas demandas. As normas culturais guiam os membros do sistema e proporcionam as regras do jogo político, ajudam a regular o número e conteúdo das demandas feitas ao sistema (EASTON, 1965, p. 100-103).

Finalmente, para o marxismo, o estudo da cultura política e das atitudes políticas ficava relegado a um segundo plano já que, tradicionalmente, consideravase a cultura política uma parte da superestrutura de uma sociedade. As normas culturais e os valores eram determinados pela base social e econômica de uma sociedade (GIBBINS, 1989, p. 4). A superestrutura representa os interesses da burguesia que assimila a ideologia inerente ao modelo dominante de produção e relações sociais de classe. A cultura se converte em algo estático porque representa as conseqüências das relações sociais entre os trabalhadores e a classe capitalista. Marx explicava a cultura em termos de dependência, enquanto Weber, ao contrário, explicava a ordem política, econômica e social como referida a uma cultura que era compartilhada pelas orientações individuais do interesse racional particular (CHILCOTE, 1994, p. 177).

Ao lado dessas perspectivas de análise, no final da década de 1980, apareceram novas linhas de análise cultural que reivindicam uma "resociologização" do conceito de cultura política. Nesse novo enfoque, ou perspectiva da interpretação, não existem diferenças entre fatos e valores, considera-se a cultura política um recurso básico que os indivíduos utilizam para guiar sua ação, proporcionando-Ihes, ao mesmo tempo, um significado, sobretudo para a análise 
dos processos de transformação e mudança (MORÁN, 1996, p. 2). Além disso, essa perspectiva abandona a idéia da cultura política como algo homogêneo e necessário para a manutenção da estabilidade do sistema político e aponta para a possibilidade de falar de diferentes culturas políticas que diferenciem os grupos componentes de uma sociedade; relacionando-se, em certa medida, com a tese sustentada por Eder (1996) de identificação da cultura política como desintegradora e não homogênea.

A nova história cultural (HUNT, 1989) apareceu como uma perspectiva de análise entre os historiadores e centrava-se em analisar a relação entre cultura política e democratização, mas entendendo-a como algo mais que uma coleção de valores subjetivos; a cultura política era definida como uma configuração de representações e práticas que existe como algo estrutural e por direito próprio (SOMERS, 1996, p. 73). As idéias e práticas políticas dos atores políticos deveriam ser vistas como resultado de suas próprias histórias.

\section{A estrutura dimensional clássica das atitudes políticas}

Segundo a definição clássica de Almond e Verba, a operacionalização do conceito de cultura política permite dividi-lo em três tipos de orientações políticas ou dimensões: cognitiva, afetiva e avaliadora. Por sua vez, cada uma dessas dimensões está composta por atitudes, crenças e valores políticos.

As orientações cognitivas referem-se ao conhecimento do sistema político e à crença nele, seus papéis e tudo o que está relacionado com esses papéis, seus inputs e outputs. As orientações afetivas incluem os sentimentos quanto ao sistema político, seus papéis pessoais e transformados; as orientações avaliadoras abrangem os juízos e opiniões sobre os objetos que tipicamente envolvem a combinação de valores e critérios padrões com informação e sentimentos (ALMOND e VERBA, 1965, p. 15). As orientações cognitivas incluem, além da quantidade de informação, sua especificidade e precisão, assim como sua capacidade para organizar e processar informação. As orientações afetivas fazem referência às distintas intensidades e diferentes qualidades: o enfado, a alegria, o desprezo e outros conceitos parecidos. As orientações avaliadoras têm a ver com o uso de diferentes critérios de valor para a formulação de opiniões e juízos. As categorias dos objetos políticos são reduzidas a seus elementos componentes.

Os objetos input incluem os meios de comunicação, os grupos de interesse, partidos políticos, poderes legislativos e o executivo em seu aspecto político. Os objetos output são classificados de muitos modos diferentes: como subcategorias que agrupam a polícia, o exército, os diferentes papéis civis e as autoridades fiscais. Ao tratar dos elementos componentes do sistema político, distinguem-se três categorias de objetos políticos: 1) papéis ou estruturas específicas: corpos 
legislativos, executivos e burocratas; 2) titulares desses papéis: monarcas, legisladores e funcionários; 3) princípios de governo, decisões ou imposições de decisões públicas e específicas.

Além das dimensões mencionadas, extraídas da operacionalização que Almond e Verba fazem de sua definição do conceito, os indicadores que trazem informação sobre essas orientações políticas são: conhecimentos e crenças sobre o sistema político, seus papéis, e de tudo o que tenha a ver com esses papéis em seus aspectos políticos (inputs) e administrativos (outputs), sentimentos acerca do sistema político, suas funções, sentimentos que desperta em si mesmo e seus sucessos, juízos e opiniões sobre objetos políticos. Esses juízos e opiniões implicam tipicamente a combinação de critérios de valor com a informação e os sentimentos. Incluem a valoração de sua própria função como sujeitos ativos e participativos na vida política.

Nas operacionalizações do conceito, inclusive utilizando definições parecidas às dadas por Almond e Verba, nem sempre se utilizam os mesmos indicadores atitudinais, ou nem sempre se conta com informação suficiente para extrair dados a respeito. Assim, Morán e Benedicto (1995) utilizam, para o caso espanhol, a classificação nas seguintes dimensões: indivíduo-cidadão como ator, a vinculação cidadão-política, a imagem do sistema político.

No entanto, essa classificação dos indicadores nas dimensões cognitiva, afetiva e avaliadora não será sustentada neste artigo tal como foi proposta pelos autores, por diversos motivos. Em primeiro lugar, porque alguns dos indicadores poderiam situar-se em mais de uma dimensão, o que limita o caráter excludente dessas dimensões. Em segundo lugar, porque a classificação de Almond e Verba foi elaborada a partir de um número maior de indicadores que os considerados neste caso e esse fato impede sua comparação e o ajuste dessa classificação para o caso espanhol. Por outro lado, o modelo preestabelecido impede a comprovação de quais são as mudanças que podem ter ocorrido na estrutura relacional entre variáveis atitudinais com o passar do tempo. Um esquema dimensional demasiado ajustado a classificações teóricas fixas impede a análise e a comprovação dessas variações, assim como dificulta a introdução de aspectos concretos que possam resultar de crucial interesse nos estudos de caso específicos.

Neste artigo, considera-se que a partir das orientações políticas dos espanhóis, conhecidas mediante respostas aos indicadores que representam atitudes, valores e comportamentos políticos, pode-se criar uma estrutura de associação que permita extrair as dimensões características desse conjunto de indicadores. Não se parte de uma classificação atitudinal predeterminada, mas sim que esta será criada a partir das atitudes mantidas pelos espanhóis em relação a objetos políticos. Esse esquema dimensional aborda de maneira um pouco mais 
nova o tratamento estrutural das atitudes políticas e, no fundo, da cultura política, tentando superar algumas das limitações anteriormente assinaladas.

\section{Elementos metodológicos e dados utilizados}

O primeiro aspecto que é preciso levar em conta no momento da medição das atitudes é especificar quais serão as variáveis de atitude e por meio delas limitar ou definir a medida a ser utilizada. Alguns autores (GONZÁLEZ BLASCO, 1986, p. 227), quando se referem a "medir" nas ciências sociais, costumam falar de atribuir símbolos numéricos a alguma magnitude ou atributo de algum acontecimento ou fato. Graças a essa definição, as medições podem ir mais além da descrição dos fenômenos, facilitam o estudo das possíveis relações entre os distintos fenômenos e ajudam a revisar os conceitos com que se trabalha. Para outros autores (ANDUIZA et al, 1999, p. 38), medir não significa necessariamente quantificar conceitos, mas estabelecer critérios para sua observação e classificação, levando em conta a presença ou ausência das propriedades do conceito. Neste artigo, medir refere-se a uma combinação das duas coisas: atribuem-se símbolos numéricos à presença ou ausência das propriedades de um conceito ou dos valores das variáveis que representam os indicadores de cultura política. Este é o critério escolhido para sua observação e a forma mais adequada para poder estabelecer gradações e escalas nas opiniões e atitudes. Além disso, essa atribuição de números permite realizar análises estatísticas e criar modelos explicativos sobre a relação entre as diferentes variáveis, que de outra maneira resultaria impossível.

Os indicadores procedem geralmente da observação ou da experiência, permitem quantificar as dimensões e convertê-las em utilizáveis para a manipulação estatística. Um indicador é a medida estatística de um conceito, da dimensão de um conceito ou de uma parte dela, baseado em uma análise teórica prévia ou integrado em um sistema coerente de medidas semelhantes. As principais funções dos indicadores são: descrever (obter informação de uma constante, estabelecer um balanço); comparar (estabelecer uma tipologia de situações em diferentes âmbitos); explicar (uns referem-se às causas e outros, aos efeitos) e prever (avaliar os efeitos e determinar possíveis inferências) (CARMONA, 1977, p.30). Mas os indicadores também podem ser utilizados para que, a partir deles, se descubra a estrutura interna de um conceito sem responder inicialmente a uma análise teórica.

Quase todos os indicadores utilizados neste artigo são subjetivos, referem-se às percepções ou interpretações dos próprios indivíduos sobre os aspectos políticos; não obstante, em relação a alguns deles, como a preferência por um regime político, se poderia falar de um indicador normativo, já que quase não existe variação nas opiniões dos espanhóis em relação a ele. 
Os indicadores que fazem referência às atitudes políticas neste artigo ${ }^{8}$ poderiam ser agrupados de acordo com as dimensões em que se divide o conceito clássico de cultura política; no entanto, considera-se que, segundo essa classificação, existem indicadores que trazem informação sobre várias dessas dimensões, o que dificulta seu posicionamento exclusivamente em uma delas. Dependendo de como se entende o significado e a informação que se pretende obter desses indicadores, podem pertencer a uma dimensão ou outra do conceito. Ademais, ao não utilizar a mesma quantidade de indicadores que Almond e Verba utilizaram, e sendo a realidade política diferente das consideradas no trabalho desses autores, sustenta-se que a diferenciação dessas dimensões atitudinais pode ser extraída dos próprios indivíduos e não ser estabelecida de antemão pelo pesquisador. Ou seja, parte-se de um conjunto de indicadores atitudinais e realizase uma análise estatística específica ${ }^{9}$ para que sejam os cidadãos entrevistados que, de acordo com a relação mantida entre as respostas e tais indicadores, permitam inferir o critério de agrupação e criação das dimensões.

Em outras pesquisas, aplicou-se essa técnica para descobrir como as atitudes perante a política se agrupam em várias dimensões empiricamente diferenciáveis (WOLLING, 2001, p. 28). Chegou-se à conclusão de que as atitudes dos cidadãos não são tão diferenciadas como sugere o modelo teórico que as divide em policy (conteúdos de diferentes campos da política), politics (processos políticos: a formação da vontade política, a decisão e a implementação) e polity (estruturas e instituições que compõem o marco em que se desenvolve a ação política) ${ }^{10}$. Existem indicadores que segundo o modelo teórico, estariam em dimensões diferentes, mas que os resultados da análise os juntaram na mesma dimensão ${ }^{11}$.

8 Os dados utilizados neste trabalho correspondem ao estudo $n^{\circ} 2387$ realizado pelo Centro de Investigaciones Sociológicas (CIS) em março de 2000, em que há um total de 14 indicadores: interesse por política, acompanhamento de informação política, socialização política, confiança em instituições políticas, importância de determinadas instituições para o funcionamento da democracia, participação social, participação política não convencional, como o afetam pessoalmente as decisões tomadas por determinadas instituições da democracia, posição ideológica pessoal e posição ideológica de partidos políticos, preferência por regime político, valoração dos partidos políticos, proximidade a partidos políticos, satisfação com o funcionamento da democracia. Alguns desses 14 indicadores constituem a agrupação de outros que fazem referência ao mesmo objeto político em forma de índice.

9 Concretamente, realiza-se uma análise fatorial com todos os indicadores considerados.

10 Esse trabalho, realizado mediante a aplicação de questionários aos habitantes da cidade de Dresden (Alemanha), pretendia analisar o uso dos meios de comunicação e as atitudes em relação à política. Seus indicadores tentavam medir, além disso, os componentes da cultura política: eficácia política, a competência política, legitimidade do governo e do sistema político, identificação com os partidos, interesse pela política e a participação não convencional.

11 Por exemplo, a posição de determinados partidos políticos em uma escala de ideologia pode ser um indicador cognitivo se é referido à capacidade e ao conhecimento de um indivíduo para ser capaz de situar esses partidos na escala. Mas também pode ser considerada como um indicador afetivo se o que se pretende comprovar é a posição adequada ou "radicalizada" de alguns partidos como resultado da 
Neste artigo, estamos conscientes de que não se pode tentar comprovar se a divisão ou estruturação dos indicadores atitudinais em dimensões se ajusta perfeitamente ou não ao modelo teórico proposto por Almond e Verba, posto que não se conta com os mesmos indicadores, e esse é um dos principais requisitos em que se baseia um bom estudo comparativo. Não obstante, considera-se que o exemplo aqui apresentado supõe uma abordagem útil no momento de sua aplicação, com informação disponível para outros casos ou momentos ao longo do tempo.

Uma vez que são os indivíduos que estabelecem as relações entre os diferentes itens mediante suas respostas às questões colocadas, construímos índices a partir deles que permitem medir essa relação com um único indicador ${ }^{12}$. Na hora de transformar um conceito, ou vários conceitos, em índices, é preciso seguir algumas etapas (BOUDON e LAZARSFELD, 1965): representação imaginada do conceito, especificação do conceito, eleição de indicadores e, finalmente, a formação dos índices. Em primeiro lugar, ter claro qual é o marco teórico em que se enquadra a análise de um problema, ou se tenta descobrir ou explicar um fenômeno. A primeira coisa que se faz é partir de um conceito que descreva as relações observadas entre os fenômenos. Em segundo lugar, no momento de concretizar em que consiste esse conceito, analisam-se os seus componentes, os quais podem ser deduzidos do conceito geral que os engloba ou, de maneira mais empírica, derivados da estrutura de suas inter-relações. Em terceiro lugar, e posto que um conceito se refere geralmente a um conjunto mais completo de fenômenos, os indicadores são os representantes de suas dimensões mais importantes. Os indicadores trazem a informação numérica que, uma vez manipulada, permite criar o índice. Por último, para construir bons índices é necessário combinar vários desses indicadores.

Neste artigo, e para a criação dos índices aqui utilizados, realizou-se uma recodificação das variáveis para que todas elas tenham uma mesma escala ${ }^{13}$. No entanto, tentando evitar alguns dos problemas que causa a ponderação dos indicadores, não se aplicou um peso diferenciado a cada um deles. Desconhece-se de início a diferente influência ou presença que possam ter os distintos indicadores entre os cidadãos, não existe um critério que a priori justifique a atribuição de pesos diferentes aos itens; por isso, os dados utilizados não estão ponderados.

\footnotetext{
distância que se quer manter em relação à posição ideológica pessoal ou do partido a que esse indivíduo se sente mais próximo.

12 Um índice é uma medida resumo de um conjunto de medidas. Os índices aqui utilizados têm como principal função apresentar uma grande quantidade de informação relativa a um mesmo indicador de maneira simples e fácil de manejar nas análises estatísticas multivariantes.

13 Os valores menores e os adjetivos ou atribuições negativas receberão sempre os valores mais baixos, enquanto as atribuições positivas ou o que reflita maior quantidade sempre serão identificados com os valores mais altos.
} 


\section{Esquema dimensional das atitudes políticas}

A aplicação da análise fatorial responde à necessidade de buscar uma agrupação das diferentes atitudes políticas em dimensões sem utilizar nenhum esquema teórico prévio sobre suas possíveis relações. Essas agrupações são criadas a partir das correlações existentes entre as respostas dadas pelos entrevistados e sem levar em conta uma agrupação teórica existente. Neste caso, e para a aplicação desta técnica, exige-se que suas variáveis sejam quantitativas; os indicadores atitudinais utilizados foram transformados em índices (14) que variam entre zero e um. Os resultados desse esquema dimensional aparecem refletidos nas Tabelas 1 e 2. A Tabela 1 proporciona informação sobre a porcentagem de variância explicada por cada um dos componentes. O modelo que inclui os três componentes explica $49 \%$ da variabilidade entre as atitudes sustentadas pelos cidadãos. A incorporação de um novo fator a este modelo não explicaria uma importante porcentagem da variabilidade dos dados, daí que o número deles tenha sido mantido em três.

Tabela 1. Variância total explicada por cada componente

\begin{tabular}{|c|c|c|c|c|c|c|c|c|c|}
\hline \multicolumn{10}{|c|}{ Variância total explicada } \\
\hline \multirow[b]{2}{*}{$\begin{array}{l}\text { Compo } \\
\text { nente }\end{array}$} & \multicolumn{3}{|c|}{ Autovalores iniciais } & \multicolumn{3}{|c|}{$\begin{array}{c}\text { Somas das saturações ao } \\
\text { quadrado da extração }\end{array}$} & \multicolumn{3}{|c|}{$\begin{array}{c}\text { Soma das saturações ao } \\
\text { quadrado da rotação }\end{array}$} \\
\hline & Total & $\begin{array}{l}\% \text { da } \\
\text { variância }\end{array}$ & $\begin{array}{c}\% \\
\text { acumulada }\end{array}$ & Total & $\begin{array}{l}\text { \% da } \\
\text { variância }\end{array}$ & $\begin{array}{c}\% \\
\text { acumulada }\end{array}$ & Total & $\begin{array}{l}\% \text { da } \\
\text { variância }\end{array}$ & $\begin{array}{c}\% \\
\text { acumulada }\end{array}$ \\
\hline 1 & 3.557 & 25.410 & 25.410 & 3.557 & 25.410 & 25.410 & 2.594 & 18.531 & 18.531 \\
\hline 2 & 2.066 & 14.759 & 40.169 & 2.066 & 14.759 & 40.169 & 2.487 & 17.765 & 36.296 \\
\hline 3 & 1.238 & 8.843 & 49.013 & 1.238 & 8.843 & 49.013 & 1.780 & 12.717 & 49.013 \\
\hline 4 & 1.047 & 7.482 & 56.495 & & & & & & \\
\hline 5 & 1.001 & 7.147 & 63.641 & & & & & & \\
\hline 6 & .816 & 5.828 & 69.469 & & & & & & \\
\hline 7 & .775 & 5.538 & 75.007 & & & & & & \\
\hline 8 & .678 & 4.844 & 79.851 & & & & & & \\
\hline 9 & .584 & 4.170 & 84.021 & & & & & & \\
\hline 10 & .554 & 3.954 & 87.975 & & & & & & \\
\hline 11 & .470 & 3.355 & 91.329 & & & & & & \\
\hline 12 & .432 & 3.085 & 94.414 & & & & & & \\
\hline 13 & .406 & 2.899 & 97.313 & & & & & & \\
\hline 14 & .376 & 2.687 & 100.000 & & & & & & \\
\hline
\end{tabular}

Método de extração: Análise de Componentes principais. 
Tabela 2. Matriz de componentes rotados

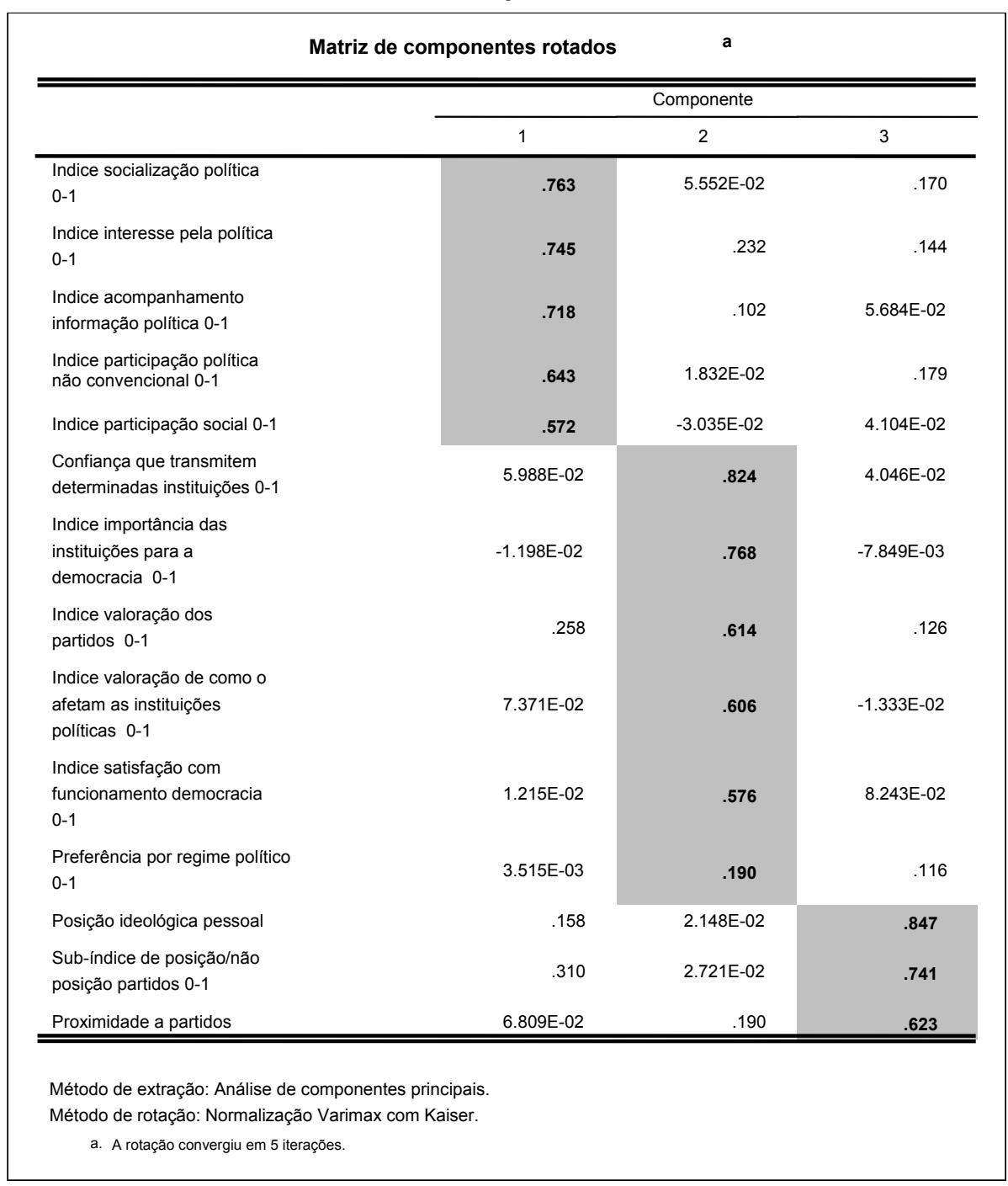

A matriz de componentes rotados (Tabela 2) mostra os três fatores extraídos e as variáveis que os formam. O primeiro fator constitui uma combinação de indicadores de implicação política: socialização política, interesse pela política, acompanhamento de informação política, participação política social e participação não convencional. O segundo fator é composto por todas as variáveis avaliadoras incluídas: importância de determinadas instituições para o funcionamento da democracia, valoração de como o afetam as decisões tomadas em determinadas instituições, valoração dos partidos políticos, satisfação com o funcionamento da 
democracia e preferência por um regime político; este último indicador tem uma baixa correlação com todos os fatores e, com efeito, poderia ser colocado em dois dos fatores, já que com o segundo componente tem uma correlação de .190 e com o terceiro componente uma correlação de .116. O terceiro dos fatores pode ser denominado afetivo-ideológico e é composto pelo autoposicionamento ideológico, a proximidade dos partidos e a posição dos mesmos na escala ideológica.

Esses três fatores refletem uma possível operacionalização do conceito de cultura política e como, de um conjunto de atitudes e orientações políticas sobre objetos políticos, descobrem-se dimensões diferenciadas entre si e com uma lógica de diferenciação bastante clara. Por outro lado, esses dados deixam claro como é difícil situar alguns indicadores somente em um dos fatores ou dimensões, e refletem o problema colocado da classificação de alguns indicadores seguindo uma estrutura teórica. Já se destacou o caso da variável "preferência de regime político", mas, além disso, pode-se ressaltar a posição ideológica dos partidos políticos. Esse indicador poderia fazer parte de dois componentes, o de implicação política e o ideológico, posto que com o primeiro tem uma correlação de .310 e com o terceiro de .741; com isso, se está apoiando a afirmação de que é muito difícil em várias situações colocar um indicador em uma única dimensão ou componente.

O posicionamento dos partidos políticos pode responder a um conhecimento do que significa o espectro ideológico e também pode responder a um posicionamento baseado em algo afetivo, dependendo da posição ideológica pessoal. Neste caso, aqueles que se sentem próximos ou identificados com um partido político costumam ser capazes de situar o resto em posturas mais extremas da que realmente pertencem. Este indicador (regime político) não é muito importante, seu coeficiente de correlação é muito baixo (.190); com efeito, é o mais baixo de todos os incluídos, porque praticamente a totalidade dos indivíduos tem a mesma opinião, não há variabilidade na opinião quanto a este indicador.

Os resultados obtidos nessa análise fatorial permitem estruturar o conjunto de variáveis atitudinais em três dimensões: implicação política, atitudes valorativas e orientações ideológico-afetivas. Se observarmos o conteúdo dessas dimensões, podemos dizer que elas guardam certa relação com a classificação teórica de Almond e Verba, embora o método de sua extração tenha sido diferente. O método de classificação das atitudes políticas em dimensões responde a uma lógica indutiva extraída dos dados possuídos e não a uma lógica dedutiva, como no caso de Almond e Verba.

\section{Dimensão de implicação política}

Essa dimensão é composta por atitudes políticas que refletem o compromisso e a implicação política dos espanhóis e explica $25,4 \%$ da 
variabilidade dos dados. Trata-se de um componente que agrupa elementos de conhecimento da realidade política e seu acompanhamento através de diferentes meios de comunicação. Além da importância concedida à socialização política como mecanismo de transmissão de valores e crenças, incluem-se determinados hábitos de comportamento, entre os quais se pode encontrar a participação social ou política não convencional.

Esses indicadores permitem captar o grau de competência política subjetiva de um indivíduo ${ }^{14}$. Se uma pessoa está consciente de que existem mecanismos mediante os quais é possível intervir em política, além de fazê-lo com o voto (participando em organizações sociais e políticas ou por meio de outras formas menos convencionais de participação que requerem um compromisso mais individualizado), ela costuma estar a par do que ocorre na política e mostra um alto interesse por questões desse tipo. A implicação política é, segundo esse modelo, a dimensão mais relevante no momento de descrever as atitudes políticas dos espanhóis e aparece claramente diferenciada das outras duas dimensões.

\section{Dimensão avaliadora}

Essa dimensão explica uma porcentagem menor da variabilidade dos dados $(14,7 \%)$. Não obstante, agrupa perfeitamente todos os indicadores atitudinais que têm a ver com as instituições políticas, marcando diferenças com respeito às outras duas dimensões. Como se ressaltou, o indicador com uma menor coerência no interior desse componente é o de preferência por um regime político ou outro. Isso se deve, em larga medida, ao fato de que quase não existem discrepâncias quanto a esse indicador nos dados, ou seja, aponta o que neste caso não existem diferenças de opinião entre os espanhóis. O fato de que possa ser um indicador afetivo. ideológico é o único inconveniente que se pode encontrar nessa dimensão, já que o resto dos indicadores está agrupado sob uma lógica muito coerente.

Entre as atitudes políticas dos espanhóis, podem diferenciar-se claramente aquelas que dizem respeito a aspectos de implicação política pessoal e aquelas que têm a ver com a avaliação de algumas instituições políticas. A valoração dessas instituições, seu funcionamento e a confiança que transmitem estão adquirindo um lugar dominante nos atuais debates sobre desafeição política e o descontentamento dos cidadãos. Por isso, o fato de todas elas formarem uma única dimensão facilita a análise da possível desafeição política observada, de maneira geral, entre os espanhóis.

\footnotetext{
${ }^{14} \mathrm{~A}$ competência política pode ser definida como o sentimento de que alguém, como cidadão dentro do sistema, é capaz de transformá-lo em alguma medida e fazê-lo de uma maneira eficaz (WIATR, 1980, p.116).
} 


\section{Dimensão ideológico-afetiva}

A terceira dimensão que estrutura as atitudes políticas aqui analisadas é a denominada ideológico-afetiva. As atitudes que têm a ver com aspectos ideológicos parecem estar claramente diferenciadas das de caráter avaliador e das de implicação política. Cabe esperar que alguns aspectos de implicação política tenham conteúdo ideológico, mas a associação entre esse tipo de indicador não chega a ser tão importante para fazer parte da mesma dimensão.

Vale a pena ressaltar como a socialização política está mais conectada com aspectos de implicação política do que com elementos ideológicos. Esse fato permite extrair a conclusão de que a socialização política na Espanha cumpre a função de transmissora de valores e atitudes políticas mais relacionadas com o desenvolvimento de atividades de implicação política (entre as quais se inclui ação ou comportamento) do que com transmissão de valores e atitudes que tenham a ver com elementos ideológicos.

Ao lado desses elementos, é preciso ressaltar também que os indicadores que guardam uma maior correlação com cada componente em cada caso são a socialização política, a confiança que transmitem determinadas instituições políticas e a posição ideológica pessoal. Essas atitudes apareceram em estudos sobre cultura política na Espanha, o que significa que sua importância continua vigente. A importância em seu momento da "re-socialização política adulta", a relevância da presença de valores e crenças democráticas, inclusive antes da transição política para a democracia, ou a ideologia são variáveis que permitem seguir definindo e descrevendo os espanhóis quanto às atitudes (MONTEIRO e TORCAL, 1990, p. 42).

\section{Conclusões}

As atitudes políticas constituíram o componente essencial da definição do conceito de cultura política. Essas atitudes permitem descrever as características das percepções, predisposições e valorações dos cidadãos em relação aos objetos políticos e a maneira como foram classificadas na maioria das análises de cultura política respondeu a uma lógica dedutiva. Isto é, partindo de uma estruturação teórica das atitudes políticas, realizou-se sua distribuição em orientações cognitivas, afetivas e avaliadoras. Em torno dessa tipologia descreveu-se a cultura política de diferentes países ou se ressaltou a subcultura política de diferentes grupos de indivíduos atendendo a uma categoria que os diferenciasse. Neste artigo, propomos um esquema dimensional indutivo, ou seja, que os próprios dados proporcionem a lógica da distribuição dos indicadores atitudinais em componentes. 
A utilização tanto do método indutivo como de técnicas de análise possui certas vantagens. Por um lado, permite a introdução de indicadores específicos relativos aos países estudo de caso, por outro lado, facilita a distribuição das próprias respostas que os cidadãos dão a indicadores atitudinais em componentes, de acordo com a correlação existente entre elas. No caso aqui proposto, a análise fatorial mostrou três dimensões em que se podem agrupar as atitudes políticas dos espanhóis: implicação política, avaliadora e ideológico-afetiva. Cada um desses componentes descreve a relação entre atitudes políticas, explicando uma importante porcentagem da variabilidade dos dados. Nesse esquema dimensional descobre-se, por exemplo, que a socialização política na Espanha está relacionada mais diretamente com aspectos de implicação e eficácia política do que com elementos ideológicos. Além disso, a recorrente legitimidade da democracia como melhor forma de governo aparece como indicador que não diferencia os espanhóis; trata-se de uma atitude que continua sem apresentar variabilidade entre eles. Por último, pode-se destacar como a posição ideológica de determinados partidos políticos na escala da ideologia responde mais a elementos afetivos do que a aspectos de conhecimento ou acompanhamento de informação política. A aplicação desse método a grupos específicos de população permitiria descobrir a presença de diferenças ou similitudes em torno de umas ou de outras dimensões.

\section{Bibliografia}

ALLEN, Stanley. Psychological needs and political behavior. A theory of personality and political efficacy. The Free Press, 1974.

ALMOND, Gabriel. Comparative political systems. Journal of politics, 18, p. 391-409, 1956.

Una disciplina segmentada. Escuelas y corrientes en las Ciencias Políticas. México: Fondo de Cultura Económica, 1999.

ALMOND, Gabriel e VERBA, Sidney. The civic culture, political attitudes and democracy in five nations. An analytic study. Boston: Little Brow, 1965.

ANDUIZA, Eva; CRESPO, Ismael e MÉNDEZ, Mónica. Metodología de la Ciencia Política. Cuadernos Metodológicos, n² 28, Madri: Centro de Investigaciones Sociológicas, 1999.

BRAITHWAITE, Valerie \& LEVI, Margaret (eds.). Trust and governance. Nova York: Russel Sage Foundation, 1998. 
BENEDICTO, Jorge. Las bases culturales de la ciudadanía democrática en España. In: CASTILLO, Pilar del e CRESPO, Ismael (eds.). Cultura política. Enfoques teóricos y análisis empíricos.

Valencia: Tirant lo Blanch, 1997.

BOUDON, Raymond e LAZARSFELD, Paul. Metodología de las ciencias sociales, I. Conceptos e indices. Barcelona: Laia, 1965.

CARMONA GUILLÉN, Jose Antonio. Los indicadores sociales hoy. Madri: Centro de Investigaciones Sociológicas, Colección Monografías, 2, 1977.

CHILCOTE, Ronald H. Theories of comparative politics: The search for a paradigm reconsidered. Boulder: Westview Press, 1994.

CLARK, Nichols \& INGLEHART, Ronald. The new political culture: Changing dynamics of support for the welfare state and other policies in postindustrial societies. In: CLARK, Terry Nichols e HOFFMAN-MARTINOT, Vincent (eds.). The new political culture. Boulder: Westview Press, 1998.

EASTON, David. A system analysis of political life. Nova York: John Wiley \& Sons, Inc., 1965.

ECKSTEIN, Harry. A culturalist theory of political change. The American Political Science Review, vol. 82, n 3, p. 789-804, 1988.

EDER, Klaus. La paradoja de la "cultura". Más allá de una teoría de la cultura como factor consensual. Zona Abierta, n 77/78, p. 95-126, 1996.

ELKINS, David J. \& SIMEON, Richard E. B. A cause in search of its effect, or what does political culture explain?. Comparative Politics, p. 127-145, jan., 1979.

EVERITT, Joanna e O'NEILL, Brenda. Citizen politics. Research and theory in Canadian political behavior. Oxford University Press, 2002.

FROMAN, Lewis A. People and politics. An analysis of the American political system. Canada: Prentice-Hall, INC., 1962.

GIBBINS, John R. (ed.). Contemporary political culture. Politics in a postmodern age. Londres: Sage, 1989.

GIRVIN, Brian. Change and continuity in liberal democratic political culture. In: GIBBINS, John. Contemporary political culture. Politics in a postmodern age. Londres: Sage, 1989. 
GONZÁLEZ BLASCO, Pedro. Medir en las ciencias sociales. In: FERRANDO, Manuel García et al. El análisis de la realidad social. Madri: Alianza, 1986.

HUNT, L. (comp.). The new cultural history. Berkeley e Los Angeles: University of California Press, 1989.

INGLEHART, Ronald. Modernización y postmodernización. El cambio cultural, económico y político en 43 sociedades. Madri: Centro de Investigaciones Sociológicas, 1998.

JAROS, Dean e V. GRAND, Lawrence. Political behavior. Choices and perspectives. Nova York, St. Martin's Press, 1974.

KAVANAGAH, Dennis. Political culture. Mcmillan Press Ltd., 1972.

LANE, Ruth. Political culture: Residual category or general theory?. Comparative Political Studies 25, p. 362-387, 1992.

MACKUEN, Michael \& BROWN, Courtney. Political context and attitude change. American Political Science Review, 81, p. 471-90, 1987.

MERELMAN, Richard M. The mundane experience of political culture. Political Communication, vol. $15, n^{\circ} 4,1998$.

MONTERO, José Ramón e TORCAL, Mariano. La cultura política de los españoles: pautas de continuidad y cambio. Sistema, nº 99, p. 39-74, 1990.

MORÁN, María Luz. Sociedad, cultura y política: continuidad y novedad en el análisis cultural. Zona Abierta, 77/78, p. 1-30, 1996.

MORÁN, María Luz e BENEDICTO, Jorge. La cultura política de los españoles. Un ensayo de reinterpretación. Madri: Centro de Investigaciones Sociológicas, 1995.

PYE, Lucian W. Political Culture. In: SILLS, David L. (ed.). International Encyclopaedia of the Social Science, vol. 12. Nova York: Macmillan and Free Press,. 1968.

ROJO, Teresa. Los supuestos de la 'nueva cultura política' respecto al comportamiento de voto. Una aplicación al caso de Madrid. Revista Española de Investigaciones Sociológicas, n 58, p.143-161, 1992.

ROSEBAUM, Walter. Political culture. Londres: Thomas Nelson \& Son, 1975. 
SEARS, David O. The role of affect in symbolic politics. In: KUKLINSKI, James H. (ed.). Citizens and politics. Perspectives from political psychology. Cambridge University Press, 2001.

SOMERS, M. ¿Qué hay de político o de cultural en la cultura política y en la esfera pública? Hacia una sociología histórica de la formación de conceptos. Zona Abierta, 77/78, p. 31-94, 1996.

THURSTONE, Louis L. Las actitudes pueden medirse. In: SUMMERS, Gene F. Medición de actitudes. México: Trillas, 1984.

WELCH, Stephen. The concept of political culture. Ipswich: St. Martin's Press, 1993.

WIATR, Jerzy J. The civic culture a marxist-sociological perspective. In: ALMOND, Gabriel A. \& VERBA, Sidney (eds.). The civic culture revisited. Boston: Little, Brown and Company, p. 103-123, 1980.

WILDAVSKY, Aaron. Choosing preferences by constructing institutions: a cultural theory of preference formation. American Political Science Review, nº 81, p. 3-21, 1987.

WOLLING, Jens. La influencia de los medios sobre la actitud ante la política. Contribuciones, $n^{\circ} 2, p$. 19-41, 2001.

ZUCKERMAN, Alan. Doing political science. An introduction to political analysis. Oxford: Westview Press, Inc., 1991. 